\title{
Determinación del costo de una flota de buses con celdas de combustible para el horizonte 2025 en el Valle de Aburrá
}

\author{
Determination of cost a fleet of fuel cell buses for the 2025 horizon in the \\ Valle de Aburrá \\ Juan Guillermo Mejía Arango, Carlos Alberto Acevedo Álvarez \\ Facultad de ingenierías, Instituto Tecnológico Metropolitano, Medellín, Colombia. \\ Correo-e: juanmejialitm.edu.co
}

\begin{abstract}
Resumen- Este artículo tiene como objetivo principal proyectar el costo de una flota de 20 buses con celdas de combustible para el horizonte 2025 en el Valle de Aburrá (Colombia). Como metodología se parte de un estudio previo donde se proyectó el costo del hidrógeno y donde se analizó la situación mundial en la cadena de producción y utilización del hidrógeno en las celdas de combustible para adaptarla a las condiciones del Valle de Aburrá. Se determinan las condiciones técnicas para la puesta en funcionamiento de una flota de 20 buses con celdas de combustible y se elabora un modelo económico para determinar el costo de implementación, de operación del sistema, los costos por kilómetro recorrido y los costos por pasajero. Como conclusiones principales se encuentra que bajo los supuestos establecidos y a pesos del 2013, los costos por pasajero para una empresa de transporte puede oscilar entre 478 \$/pasajero y 773 $\$$ pasajero, lo que da una factibilidad económica a la implementación de un sistema de este tipo, esto sin considerar los beneficios ambientales, de salud, de calidad de vida $y$ de seguridad energética al hacer una diversificación de la misma.
\end{abstract}

Palabras clave - Celdas de combustible, hidrógeno, transporte sostenible, energía renovable.

Abstract - This article has main objective to project the cost of a fleet of 20 fuel cell buses for 2025 in the Valle del Aburrá (Colombia). As methodology it is begins of a previous study which projected the cost of hydrogen and where was analyzed the world situation in the production and use of hydrogen in fuel cells to adapt to the conditions of the Valle del Aburrá. The technical conditions are determined for the operation of a fleet of 20 fuel cell buses and an economic model was developed to determine the cost of implementation, of system operation, the cost per kilometer and cost per passenger. The main conclusions are that under the assumptions made and 2013 pesos, the costs per passenger for a transport company can vary from 478 $\$$ /passenger to $773 \$$ /passenger, giving an economic feasibility to the implementation of a system of this type, without considering the profit environmental, health, quality of life and energy security by diversifying of the same.
KeyWords -Fuel cells, hydrogen, sustainable transport, renewable energy.

\section{INTRODUCCIÓN}

Las celdas de combustible operando con hidrógeno se perfilan como una opción importante para aplicarlas al sector transporte. Con ellas es reducido el impacto al medio ambiente provocado por el sistema convencional; es decir aquellos que operan con combustibles derivados del petróleo; además existe la posibilidad de tener mayor eficiencia en el uso de la energía, diversificar el uso de las fuentes energéticas y tener menor dependencia de los derivados del petróleo. Las celdas de combustible consisten en dispositivos que mediante un proceso electroquímico y con la ayuda de un catalizador, transforman la energía química de un combustible (generalmente hidrógeno) en energía eléctrica y agua. Esta transformación energética ocurre con un alto rendimiento $(>50 \%)$ [1]. Las celdas de combustible también tienen aplicación en la generación de energía eléctrica en sistemas portátiles y estacionarios.

\section{CONTENIDO}

\section{A. Generalidades}

Las celdas de combustible facilitan la producción de energía eléctrica y agua mediante la inyección de hidrógeno y oxígeno. Las reacciones que tienen lugar se muestran en (1), (2) y (3) [2] y [3]. 
En el ánodo

En el cátodo

Reacción completa

$$
\begin{aligned}
& 2 \mathrm{H}_{2} \rightarrow 4 H^{+}+4 e^{-}(1) \\
& \mathrm{O}_{2}+4 H^{+} \rightarrow 2 \mathrm{H}_{2} \mathrm{O}(2) \\
& 2 \mathrm{H}_{2}+\mathrm{O}_{2} \rightarrow 2 \mathrm{H}_{2} \mathrm{O}(3)
\end{aligned}
$$

En la tabla 1 se muestran las principales familias de pilas de combustible, la celda de combustible de membrana de intercambio de protones PEMFC (Proton Exchange Membrane Fuel Cell) se perfila como la tecnología que se utilizará en los futuros vehículos equipados con celdas de combustible, su eficiencia es mayor de $40 \%$ [7] y [22]. En una celda PEMFC con eficiencia del $55 \%$, un $\mathrm{kg}$ de $\mathrm{H}_{2}$ con un contenido energético de $120.1 \mathrm{Mj}$ puede generar $18.5 \mathrm{kWh}$ [1].

En las celdas PEMFC es preferible operar con hidrógeno proveniente del proceso de la electrólisis. Si el hidrógeno es obtenido a partir del gas natural - GN; se debe purificar, debido a que los catalizadores de platino empleados en las PEMFC tienen poca tolerancia a los compuestos de sulfuro o de monóxido de carbono y la descomposición de la membrana

\begin{tabular}{|c|c|c|}
\hline Tipo & $* \eta \%$ & Aplicaciones \\
\hline Alcalina (AFC) & $35-40$ & $\begin{array}{l}\text { De } 10 \text { a } 100 \mathrm{~kW} \text { (electricidad), militar, } \\
\text { espacial, transporte, alta densidad de } \\
\text { potencia, no tolera el } \mathrm{CO}_{2} .\end{array}$ \\
\hline $\begin{array}{l}\text { Polimérica } \\
\text { (PEMFC) }\end{array}$ & $40-50$ & $\begin{array}{l}\text { De algunos } \mathrm{mW} \text { a } 500 \mathrm{~kW} \text { (electricidad), } \\
\text { calor y electricidad (residencial, industria), } \\
\text { transporte, portátiles, alta densidad de } \\
\text { potencia, se contamina con CO. }\end{array}$ \\
\hline $\begin{array}{l}\text { Conversión } \\
\text { directa de } \\
\text { Metanol } \\
\text { (DMFC) }\end{array}$ & $40-50$ & $\begin{array}{l}\text { De } \mathrm{mW} \text { a menos de } 10 \mathrm{~kW} \text { (electricidad), } \\
\text { pequeña potencia portátil, militar, transporte, } \\
\text { baja eficiencia, densidad de potencia media, } \\
\text { alto contenido en platino. }\end{array}$ \\
\hline $\begin{array}{c}\text { Ácido } \\
\text { Fosfórico }\end{array}$ & $40-50$ & $\begin{array}{l}\text { Electricidad, calor y electricidad (hasta el } \\
85 \% \text { de eficacia), hasta } 10 \mathrm{MW} \text {, densidad de } \\
\text { potencia media, sensible al CO. }\end{array}$ \\
\hline $\begin{array}{l}\text { Carbonato } \\
\text { Fundido }\end{array}$ & \multirow[t]{2}{*}{$50-60$} & \multirow{2}{*}{$\begin{array}{l}\text { Electricidad, calor y electricidad (hasta el } \\
85 \% \text { de eficacia), hasta } 100 \mathrm{MW} \text {, baja } \\
\text { densidad de potencia, necesita reciclar } \mathrm{CO}_{2} \text {. }\end{array}$} \\
\hline (MCFC) & & \\
\hline Oxido Solido & \multirow[t]{2}{*}{$45-55$} & \multirow{2}{*}{$\begin{array}{c}\text { Electricidad, calor y electricidad (hasta el } \\
85 \% \text { de eficacia), hasta } 100 \mathrm{MW} \text {, media-alta } \\
\text { densidad de potencia, acepta el CO como } \\
\text { combustible. }\end{array}$} \\
\hline (SOFC) & & \\
\hline
\end{tabular}
aumenta y la eficiencia de la celda disminuye con la aparición de impurezas.

Tabla 1: Principales familias de pilas de combustible [12]

El costo de los vehículos de celdas de combustible es la suma de los costos de todos los elementos que se requieren para su construcción, destacándose principalmente la celda de combustible, el motor eléctrico, los sistemas de control y de conversión de energía eléctrica, los sistemas de almacenamiento de combustible, baterías y carrocería. La proyección del costo de cada uno de estos elementos depende sensiblemente de los adelantos tecnológicos y de la masificación de producción [4].

Para el costo de operación de los vehículos con celdas de combustible se combinan los costos de los vehículos con otras variables que dependen del precio del hidrógeno y de la eficiencia que se logre de todo el conjunto en operación. El impacto ambiental de este sistema de transporte comparado con los sistemas convencionales también debería ser involucrado en un análisis de costos en la medida que se puedan obtener beneficios tributarios.

Se espera que para el año 2050, las celdas de combustible tendrán sus costos por debajo de 100 USD/kW [1] y [5]. Según el Departamento de Energía de EE.UU para una producción a gran escala de celdas de combustible, se puede alcanzar la meta de $30 \mathrm{USD} / \mathrm{kW}$. La eficiencia de las celdas de combustible es $60 \%$ para potencias de salida de $100 \mathrm{~kW}$ que es más del doble de la eficiencia de un vehículo de combustión interna actual. Los buses con celdas de combustible han demostrado tener una eficiencia $40 \%$ más alta que aquellos que operan con diésel y más del doble que la correspondiente a los buses de combustión interna con gas natural [6].

El costo de la estructura para un vehículo de $80 \mathrm{~kW}$ con celda de combustible puede ser de USD 16670 o 208 USD/kW en el 2005. A 2005 el costo de la celda de combustible es aproximadamente el $85 \%$ del total del vehículo, pero esta participación irá disminuyendo hasta caer al 22\% en 2030 [7]. Se estima que el costo de un FCV (Fuel cell vehicle) de 80 kW podría estar entre USD 22000 y USD 27000 en 2030. Por esto, el costo de los FCV puede ser superior al de los vehículos convencionales en un rango que va de USD 2200 a USD 7625.

Teniendo en cuenta el costo del vehículo con vida útil de 5 años y el costo del combustible, en el año 2035 la operación de un vehículo con celdas de combustible se proyecta que pueda costar $0.58 \mathrm{USD} / \mathrm{km}$ frente a $0.61 \mathrm{USD} / \mathrm{km}$ de un vehículo de combustión interna. Para este año se asume que el rendimiento de los vehículos con celdas de combustible será 1.62 veces el de los vehículos de combustión interna [5]. El costo del motor eléctrico puede disminuir de $25 \mathrm{USD} / \mathrm{kW}$ a 15 USD/kW (en total de 2000 USD a 1200 USD para un vehículo de $80 \mathrm{~kW})$ [8].

En 2010 existen más de 400 proyectos piloto que emplean las celdas de combustible en vehículos. La mayoría de celdas utilizadas en este sector corresponden a las PEMFC (Proton exchange membrane fuel cells) [9]. Los buses, los vehículos de reparto y los montacargas son el nicho de mercado donde los vehículos con celdas de combustible pueden ser competitivos frente a los tradicionales motores de combustión interna que operan con gasolina y diesel [6]. Para que los buses sean competitivos; el sistema de celdas de combustible debe reducir sus costos hasta $200 \mathrm{USD} / \mathrm{kW}$ [7]. La investigación e inversiones en las celdas de combustible se han intensificado en el mundo [11]. El mercado de las celdas de combustible aumentó más de $300 \%$ con respecto a 2008 . En este año se distribuyeron 30000 sistemas de celdas de combustible. En el Reino Unido se tiene proyectado que para el 2030 se venderán cerca de 325000 vehículos con celdas de combustible (para un total de 1,6 millones), atendidos por 1100 estaciones de suministro de hidrógeno. Para este año el 
costo relativo de los vehículos de celdas de combustible y los de combustión interna serán iguales. En California (USA) se proyecta tener para 2016; 68 estaciones de hidrógeno para atender 20000 vehículos y para 2017 ya se pueden tener cerca de 50000 vehículos [10].

La mayoría de buses con celdas de combustible trabajan con tecnología que emplea las membranas de intercambio de protones (PEMFC), con potencias que van desde $70 \mathrm{~kW}$ (híbridos con batería) hasta $250 \mathrm{~kW}$. La mayoría de estos buses emplean hidrógeno gaseoso comprimido [4] y [12].

Un ejemplo de estos buses es el Daimler Chrysler Citaro, el cual tiene una autonomía comprendida entre 200 y $300 \mathrm{~km}$, puede transportar entre 60 y 70 pasajeros y está equipado con una celda de PEM de $250 \mathrm{~kW}$ (200 kW de potencia en el eje) y tiene una capacidad de almacenamiento de combustible hasta $44 \mathrm{~kg}$ de $\mathrm{H}_{2}$ gaseoso comprimido a 350 bar. El precio de este vehículo es de 1,5 millones de dólares (6000 USD/kW) que incluye el costo de mantenimiento por dos años. El costo incremental con respecto a vehículos convencionales de la misma potencia está entre 0,5 y 1,5 millones de dólares [4] y [13].

Según [7] y [14] los buses pueden contar con motores eléctricos de $205 \mathrm{~kW}$, presión en el tanque de 350 bar y velocidad de $80 \mathrm{~km} / \mathrm{h}$. En cuanto a los automóviles; pueden trabajar con presiones de 350 y 700 bar, celdas de $72 \mathrm{~kW}$, motores de $65 \mathrm{~kW}$, baterías de 6,5 Ah con autonomías de 177 $\mathrm{km}$ y velocidades de $140 \mathrm{~km} / \mathrm{h}$.

En un estudio de transporte urbano con hidrógeno en Valladolid España entre 2005 y 2006; tasaron el costo de cada bus Mercedes Benz Citaro en 1,5 millones de dólares que incluye mantenimiento y operación [13]. Las características de los buses propuestos en Valladolid se muestran en la Tabla 2 .

\section{A. Resultados}

Colombia no dispone de proyectos para la producción comercial de celdas de combustible y su uso en el sector transporte es consecuencia del desarrollo logrado a nivel mundial. Los proyectos que dependan primordialmente de la variable económica; tendrán que esperar hasta el momento en el cual en el mundo sucedan las condiciones para hacerlo; es decir que el desarrollo del mercado de las celdas de combustible y todo su entorno para su utilización estén en crecimiento. Cuando el aspecto ambiental y el de seguridad en la disponibilidad de recursos energéticos sean predominantes; los proyectos liderados por el gobierno pueden adelantarse al desarrollo pleno de este mercado en el mundo. Según lo planteado, para implementar proyectos en el 2025 en el Valle de Aburrá, se tendrá que contar con el apoyo decidido de los entes gubernamentales y esperar que desde el punto de vista mercado de las celdas de combustible, ocurra un desarrollo suficiente para mantenerlo.
En la tabla 3 se presentan los supuestos para realizar la proyección de costos de vehículos y buses de celdas de combustible en Colombia, estos resultan principalmente del análisis detallado de proyecciones realizadas de precios de las celdas de combustible a mediano y largo plazo, del desarrollo del mercado potencial y las mejoras tecnológicas.

\begin{tabular}{|c|c|c|c|}
\hline Altura & $3,7 \mathrm{~m}$ & Autonomía & $\begin{array}{c}200 \mathrm{~km}(5 \mathrm{~km} / \mathrm{Kg} \\
\left.\text { de } \mathrm{H}_{2}\right)\end{array}$ \\
\hline Largo & $12 \mathrm{~m}$ & $\begin{array}{c}\text { Tanques: } \\
9 \text { cilindros de } \\
205 \text { litros cada } \\
\text { uno } \\
\end{array}$ & $\begin{array}{c}(46.125 \mathrm{l} / \mathrm{kg} \text { de } \\
\left.\mathrm{H}_{2}\right)(12 \\
\left.\text { galones/kg de } \mathrm{H}_{2}\right)\end{array}$ \\
\hline Ancho & $2,55 \mathrm{~m}$ & Ruido & $45 \mathrm{~dB}$ a $10 \mathrm{~m}$ \\
\hline Pasajeros & 60 a 80 & Motor eléctrico & $205 \mathrm{~kW}$ \\
\hline $\begin{array}{c}\text { Potencia } \\
\text { neta en el eje }\end{array}$ & $\begin{array}{c}190 \\
\mathrm{~kW} \mathrm{a} \\
2100 \\
\mathrm{rpm}\end{array}$ & $\begin{array}{l}\text { Celdas de } \\
\text { combustible }\end{array}$ & $\begin{array}{c}2 \text { celdas de } 150 \\
\mathrm{~kW}\end{array}$ \\
\hline Eficiencia & $\begin{array}{c}35 \text { a } 45 \\
\%\end{array}$ & $\begin{array}{c}\text { Corriente } \\
\text { nominal }\end{array}$ & $300 \mathrm{~A}$ \\
\hline Presión & 350 bar & $\begin{array}{c}\text { Tensión de } \\
\text { salida }\end{array}$ & $280 \mathrm{VDC}$ \\
\hline $\begin{array}{c}\text { Capacidad } \\
\text { de } \\
\text { almacenamie } \\
\text { nto }\end{array}$ & $\begin{array}{l}40 \mathrm{~kg} \\
\text { de } \mathrm{H}_{2} .\end{array}$ & \multirow[t]{2}{*}{$\begin{array}{l}\text { Peso de cada } \\
\text { celda }\end{array}$} & \multirow[t]{2}{*}{$96 \mathrm{~kg}$} \\
\hline Velocidad & $\begin{array}{c}80 \\
\mathrm{~km} / \mathrm{h}\end{array}$ & & \\
\hline
\end{tabular}

Tabla 2. Características de los buses con celdas de combustible Fuente [13]

\begin{tabular}{|c|c|c|c|}
\hline Supuestos & Valor & $\begin{array}{c}\text { Unida } \\
\text { d }\end{array}$ & Sustentación \\
\hline $\begin{array}{l}\text { Costo celdas } \\
\text { para } \\
\text { automóviles }\end{array}$ & 100 & $\begin{array}{l}\mathrm{USD} / \mathrm{k} \\
\mathrm{W}\end{array}$ & $\begin{array}{l}\text { Las proyecciones } \\
\text { muestran que este valor } \\
\text { puede ser alcanzado }\end{array}$ \\
\hline $\begin{array}{l}\text { Costo celdas } \\
\text { para buses }\end{array}$ & 200 & $\begin{array}{c}\mathrm{USD} / \mathrm{k} \\
\mathrm{W}\end{array}$ & $\begin{array}{l}\text { Valor requerido para ser } \\
\text { competitivo }\end{array}$ \\
\hline $\begin{array}{l}\text { Producción } \\
\text { mundial de } \\
\text { PEMFC }\end{array}$ & 500000 & u/año & $\begin{array}{l}\text { Valor estimado para el } \\
\text { desarrollo de mercado }\end{array}$ \\
\hline $\begin{array}{l}\text { Relación costo } \\
\text { celda/vehículo }\end{array}$ & 30 & $\%$ & $\begin{array}{c}\text { Del análisis de } \\
\text { proyección de costos }\end{array}$ \\
\hline Vida útil celda & 5 & años & Mejoras tecnológicas \\
\hline Vida útil FCV & 15 & años & Lo corriente \\
\hline $\begin{array}{l}\text { Rendimiento } \\
\text { en vehículos }\end{array}$ & 100 & $\begin{array}{l}\mathrm{km} / \mathrm{kg} \\
\mathrm{de} \mathrm{H}_{2}\end{array}$ & Datos de eficiencia \\
\hline $\begin{array}{l}\text { Rendimiento } \\
\text { en buses }\end{array}$ & 13 & $\begin{array}{l}\mathrm{km} / \mathrm{kg} \\
\text { de } \mathrm{H}_{2}\end{array}$ & Proyecciones \\
\hline Sobrecosto & 30 & $\%$ & $\begin{array}{c}\text { Por importaciones, } \\
\text { dependencia tecnológica } \\
\text { y lentitud del mercado }\end{array}$ \\
\hline
\end{tabular}

Tabla 3. Supuestos para realizar la proyección de costos Fuente: Elaboración propia.

En la Tabla 4 se presenta el estimativo del costo correspondiente a los buses de $250 \mathrm{~kW}$ y los automóviles de $80 \mathrm{~kW}$ al año 2025 bajo los supuestos planteados.

\begin{tabular}{l|l|l} 
Tipo de & Potencia & Costo
\end{tabular}




\begin{tabular}{|c|c|c|}
\hline vehículo & $\mathrm{kW}$ & USD \\
\hline Buses & 250 & 216667 \\
\hline Automóviles & 80 & 34667 \\
\hline
\end{tabular}

Tabla 4. Costo proyectado buses y vehículos a 2025

Fuente: Elaboración propia.

1. Infraestructura Requerida en el Valle de Aburrá para una flota de 20 buses.

Se requiere de una infraestructura que tenga capacidad de atender las necesidades de operación y mantenimiento de los buses y automotores. La infraestructura básica está compuesta por las estaciones de suministro de hidrógeno, por la flota de buses y por los centros de mantenimiento de los vehículos.

De acuerdo a las ofertas del mercado y las necesidades de transporte se propone que cada bus tenga una autonomía entre 200 y $300 \mathrm{~km}$, capacidad para transportar 75 pasajeros, cuente con dos celdas de combustible de $125 \mathrm{~kW}$ a 600 voltios DC y corriente nominal de 210 amperios, tanques de almacenamiento para $45 \mathrm{~kg}$ de $\mathrm{H}_{2}$ gaseoso a una presión de $700 \mathrm{bar}$, velocidad de $80 \mathrm{~km} / \mathrm{h}$, motor eléctrico de corriente alterna de $200 \mathrm{~kW}$ nominales. Las dimensiones aproximadas de cada bus son de 12 metros de largo, $2.55 \mathrm{~m}$ de ancho y 3.5 $\mathrm{m}$ de alto [5], [4], [13] y [15].

Cada bus debe contar con los módulos que garanticen su buen funcionamiento: sistema de refrigeración, sistema de pilas de combustible para la generación de la energía eléctrica, sistema para control de la presión de hidrógeno, sistema para comprimir el aire que requiere la celda, sistema de conversión y control de energía eléctrica, sistema de tracción y servicios auxiliares y sistema de interconexión de conductos [4] y [13]. Una flota con buses y autos con celdas de combustible puede circular por el sistema normal de vías de las ciudades. Debido a sus cualidades para disminuir al impacto ambiental producido por el sector transporte, se pueden habilitar rutas especiales donde estos vehículos puedan reemplazar los medios de transporte de alto impacto ambiental en algunos sitios del Valle de Aburrá. El sistema METROPLÚS que se está desarrollando en la ciudad resulta muy atractivo para la introducción de esta tecnología.

\section{Estaciones de servicio}

Para el suministro de hidrógeno a una flota de buses se requiere de estaciones de abastecimiento ubicadas preferiblemente en el área de influencia de funcionamiento de este sistema de transporte. En la medida que se empiece a desarrollar el mercado y se tenga que garantizar el suministro a nuevos automotores; se tendrá que ampliar el número y cobertura de las estaciones. Esta situación ocurre con el sistema de transporte de gas natural vehicular - GNV donde inicialmente se instaló una infraestructura básica de estaciones y vehículos y luego se fue ampliando de acuerdo al desarrollo del mercado.
En la Tabla 5 aparece un la proyección de las estaciones de suministro de hidrógeno según los casos de requerimientos de transporte y la capacidad de abastecimiento. Para esto se parte de las necesidades de producción diaria de hidrógeno y se relaciona con las capacidades de la producción de equipos que se encuentran en el mercado.

\begin{tabular}{|l|c|c|c|c|c|c|}
\hline \multicolumn{1}{|c|}{$\begin{array}{c}\text { Tipo de } \\
\text { vehículo }\end{array}$} & $\begin{array}{c}\text { Caso } \\
\mathbf{1}\end{array}$ & $\begin{array}{c}\text { Caso } \\
\mathbf{2}\end{array}$ & $\begin{array}{c}\text { Caso } \\
\mathbf{3}\end{array}$ & $\begin{array}{c}\text { Caso } \\
\mathbf{4}\end{array}$ & $\begin{array}{c}\text { Caso } \\
\mathbf{5}\end{array}$ & $\mathbf{U n}$ \\
\hline Buses & 20 & 120 & 200 & 400 & 4272 & $\mathrm{u}$ \\
\hline Carros & 0 & 0 & 24750 & 49500 & 85447 & $\mathrm{u}$ \\
\hline $\begin{array}{l}\text { Consumo } \mathrm{H}_{2} \\
\text { buses }\end{array}$ & 960 & 5760 & 9600 & 19200 & 205074 & $\begin{array}{c}\mathrm{kg} / \\
\text { día }\end{array}$ \\
\hline $\begin{array}{l}\text { Consumo } \mathrm{H}_{2} \\
\text { autos }\end{array}$ & - & - & 13562 & 27123 & 46820 & $\begin{array}{c}\mathrm{kg} / \\
\text { día }\end{array}$ \\
\hline $\begin{array}{l}\text { Total } \\
\text { consumo }\end{array}$ & 960 & 5760 & 23162 & 46323 & 251894 & $\begin{array}{c}\mathrm{kg} / \\
\text { día }\end{array}$ \\
\hline $\begin{array}{l}\text { Capacidad de } \\
\text { producción } \\
\text { kg/día }\end{array}$ & \multicolumn{7}{|l|}{} \\
\hline 50 & 19 & 115 & 463 & 926 & 5038 & $\mathrm{u}$ \\
\hline 500 & 2 & 12 & 46 & 93 & 504 & $\mathrm{u}$ \\
\hline 1300 & 1 & 4 & 18 & 36 & 194 & $\mathrm{u}$ \\
\hline
\end{tabular}

Tabla 5. Proyección estaciones de suministro de hidrógeno Fuente: Elaboración propia.

Las estaciones con capacidad de producción de $500 \mathrm{~kg} /$ día y $1300 \mathrm{~kg} /$ día de $\mathrm{H}_{2}$ resultan aceptables para atender una flota de 20 buses porque en un principio se facilita más la instalación y puesta en servicio de pocas estaciones sin sacrificar la atención de la demanda de hidrógeno requerida. Además, el servicio de los 20 buses se limita a un área determinada del Valle de Aburrá, lo que posibilita instalar uno o dos sitios de abastecimiento ubicadas en la zona de influencia para prestación del servicio. Para incrementos sustanciales del parque automotor con celdas de combustible; las estaciones de suministro con capacidad de $1300 \mathrm{~kg} /$ día resultan más recomendables en vista de limitar el número de estaciones a instalar en la ciudad. Con esta capacidad de suministro se deberían instalar entre 1 y 194 estaciones según sea el caso de análisis, cada estación debe adaptar el número de bahías de atención de tal forma que puedan atender la flota de buses y de carros. Para esto se relaciona el número de carros por atender con el número de estaciones determinadas. De esta forma, si se disponen de 85500 vehículos operando con hidrógeno se necesitarían 36 estaciones, cada estación debe estar en capacidad de atender 2370 carros. Para atender 4270 buses se requieren 158 estaciones con lo que cada estación puede atender 27 buses diariamente.

De acuerdo este análisis y a la disposición del mercado se propone una estación con electrolizadores con capacidad de producir $1300 \mathrm{~kg} \mathrm{de} \mathrm{H}_{2} /$ día para atender una flota de 20 buses. La capacidad de almacenamiento debe ser $2000 \mathrm{~kg}$ de $\mathrm{H}_{2}$ a 700 bar [9]. Para este efecto la estación debe contar con 30 electrolizadores con capacidad individual de $50 \mathrm{~kg}$ de $\mathrm{H}_{2}$ /día y presión de salida de 50 bar. Se debe disponer de una unidad eléctrica para conversión de corriente alterna - CA a corriente directa - CD requerida para alimentar los electrolizadores. 
En las estaciones también se deben disponer de compresores eléctricos que comprimen el hidrógeno hasta la presión de almacenamiento y el depósito de agua desionizada con una capacidad de $330 \mathrm{~m}^{3}$ mensuales en régimen nominal (cada electrolizador requiere $18 \mathrm{~m}^{3}$ ) [13]. Para almacenar el hidrógeno a 700 bar se requieren de 30 tanques (cada tanque tiene una capacidad de almacenar $70 \mathrm{~kg}$ de $\mathrm{H}_{2}$ ). El área requerida para producir, distribuir, parquear $\mathrm{y}$ hacer mantenimiento a los 20 buses es aproximadamente $4000 \mathrm{~m}^{2}$ (adaptado de [13]).

\section{Análisis económico de una flota de 20 buses.}

Para determinar el costo una flota de buses con celdas de combustible se elaboró un modelo económico que relaciona las variables requeridas para llegar hasta el detalle de costo por pasajero y por kilómetro recorrido. El modelo permite encontrar entre otras; el consumo y costo de hidrógeno, el número y costo de las estaciones de suministro de hidrógeno, el costo de operación y mantenimiento, el consumo y costo de la energía eléctrica y el gas natural, el costo de instalación de la flota, impuestos y terreno, el margen para el productor de hidrógeno, costo de los sistemas de reformado de Metano con vapor - SMR, número y costo de vehículos y flota de buses, costo celdas y costo de cada bus en operación.

El modelo económico definido adapta la estructura definida en (4).

$$
L C C=C+M+E+R-S(4)
$$

Donde LCC es el costo del proyecto, $\mathrm{C}$ es el costo de capital, $\mathrm{M}$ corresponde al costo de mantenimiento, $\mathrm{E}$ es el costo de operación en términos de energía, $\mathrm{R}$ es el costo de reposición, $\mathrm{S}$ son los ahorros debidos a costos evitados [16].

El Costo anualizado se realiza según (5), [18] y [19].

$$
A=\frac{C * i *[(1+i)]^{n}}{[(1+i)]^{n}-1}
$$

Dónde:

A: Valor anual del capital

i: Tasa de rentabilidad

n: Número de períodos del proyecto

El Costo anualizado con valor de salvamento se encuentra según (6) y (7)

$$
C A n=A-A V S F(6)
$$

Donde:

CAn: Costo anualizado de capital teniendo en cuenta el valor de salvamento.

AVSF: Costo anualizado del valor del activo al final del proyecto.

$$
A V S F=\left(F * \frac{i}{[(1+i)]^{n-1}}\right)(7)[18]
$$

Dónde:

F: Valor del activo al final del proyecto

Según el informe "The Research and Innovative Technology Administration (RITA)", el consumo promedio de combustible de los buses convencionales es de $10 \mathrm{~km} /$ galón [20]. Con otras fuentes energéticas es $5.5 \mathrm{~km} /$ galón. Como se mostró anteriormente; se espera que los vehículos de celdas de combustible dupliquen la eficiencia de los vehículos convencionales a través de las mejoras tecnológicas y por la producción en serie de esta tecnología, ya que la eficiencia de los buses con celda de combustible puede estar alcanzando los $20 \mathrm{~km} / \mathrm{kg}$ de $\mathrm{H}_{2}$ en 2020 [7] y [21], para efectos de hacer el análisis de costos se tomará un valor de $13 \mathrm{~km} / \mathrm{kg}$ más conservador que el proyectado pero es el doble de sistemas actuales (a 2013).

El cálculo del costo anual de cada bus al año 2025 es

\begin{tabular}{|c|c|c|}
\hline \multicolumn{3}{|c|}{ Costo consumo $\mathbf{H}_{2}$} \\
\hline $\begin{array}{c}\text { Con energía eléctrica - } \\
\text { EE a }(\$ / \mathrm{kWh})\end{array}$ & USD/año & Producción $\mathrm{H}_{2}$ \\
\hline 233 & 61110 & Descentralizada \\
\hline 69 & 24738 & Centralizada \\
\hline 50 & 20253 & Centralizada \\
\hline \multicolumn{3}{|l|}{ Con GN a $\left(\$ / \mathrm{m}^{3}\right)$} \\
\hline 642 & 39735 & Descentralizada \\
\hline 450 & 35110 & Descentralizada \\
\hline 255 & 32797 & Centralizada \\
\hline
\end{tabular}
aproximadamente 46000 USD. El costo de consumo de $\mathrm{H}_{2}$ por año, depende del precio de la energía eléctrica y del gas natural, los cuales se muestran en la tabla 6 .

Tabla 6. Costo anual del consumo de $\mathrm{H}_{2}$ para cada bus de celda de combustible

Fuente: Elaboración propia.

Con producción descentralizada; el GN presenta el costo más favorable con cerca de 35000 USD/año por bus, con la producción descentralizada de hidrógeno, la producción mediante el proceso de la electrólisis se obtiene el valor más bajo con 20253 USD/año por bus. Por ejemplo; se tenía un costo de producción de hidrógeno de $8.72 \mathrm{USD} / \mathrm{kg}$ de $\mathrm{H}_{2}$ cuando la producción es descentralizada por el proceso de la electrolisis, con una tarifa eléctrica de $\$ 233 / \mathrm{kWh}$. Tomando un consumo de $24 \mathrm{~kg}$ de $\mathrm{H}_{2}$ /día para hacer un recorrido de $320 \mathrm{~km}$, cada bus consumiría al año $7008 \mathrm{~kg}$ de $\mathrm{H}_{2}$, lo que resultaría en un costo anual de USD 61110 por consumo de hidrógeno.

El costo total de funcionamiento de un bus, incluyendo: costo del bus, operación y mantenimiento y el combustible consumido; se muestra en la tabla 7. Estos costos no incluyen la contratación de personal encargado de la administración del bus ni los impuestos por la operación del mismo.

El costo del proyecto total para los 20 buses se estima en 1619218 USD/año cuando se toma en cuenta la producción descentralizada con GN y de 1322079 USD con producción centralizada a partir de la electrólisis. El proyecto total tiene 
un costo de 32'384.374 USD y 26'441.590 USD respectivamente. El peor de los casos se obtendría con la producción descentralizada de $\mathrm{H}_{2}$ a partir de la electrólisis con tarifa de $\$ 233 / \mathrm{kWh}$ donde el costo del proyecto es de 42'784.246 USD. El proyecto que se desarrolló en Sao Pablo Brasil para 8 buses está estimado en un valor de 16 millones de dólares [17]. Para calcular el costo total de un bus en funcionamiento se suman el costo de consumo de hidrógeno al costo anualizado de un bus. El costo anualizado de cada bus se obtiene a partir del valor del bus, del costo de operación y mantenimiento y el costo anualizado por recambio de celdas ver tabla 6. Para el caso de la tarifa de $\$ 233 / \mathrm{kWh}$ se suman a los 61110 dólares correspondientes al consumo de hidrógeno, 45851 dólares correspondientes al costo anualizado de cada bus, para un total de 106961 dólares.

\begin{tabular}{|c|c|c|}
\hline \multicolumn{3}{|c|}{ Costo total de cada bus en operación } \\
\hline Con EE a (\$/kWh) & USD/año & Producción $\mathbf{H}_{\mathbf{2}}$ \\
\hline 233 & 106961 & Descentralizada \\
\hline 69 & 70589 & Centralizada \\
\hline 50 & 66104 & Centralizada \\
\hline Con GN a (\$/m3) & & \\
\hline 642 & 85586 & Descentralizada \\
\hline 450 & 80961 & Descentralizada \\
\hline 255 & 78648 & Centralizada \\
\hline
\end{tabular}

Tabla 7. Costo total de buses en funcionamiento empleando celdas de combustible.

Fuente: Elaboración propia.

Los costos por kilómetro recorrido y por pasajero del sistema en operación se muestran en la Tabla 8. Se observa que estos costos dependen del tipo de producción y del costo de la energía eléctrica y del gas natural.

Como ejemplo para encontrar el costo por kilómetro recorrido, se lleva el costo anual a un costo diario (dividiendo por 365 y aplicando un factor de utilización del bus) y se divide por los kilómetros recorridos diariamente. Se tiene entonces en (8) y (9):

$$
\begin{gathered}
\frac{\text { Costo }}{k m}=\frac{106961\left(\frac{U S D}{a n ̃ o}\right)}{365 \text { días } * 0.8 * 320 \frac{\mathrm{km}}{d^{\prime} a}}(8) \\
\frac{\text { Costo }}{\mathrm{km}}=1.14 \frac{\text { USD }}{\mathrm{km}}
\end{gathered}
$$

\begin{tabular}{|c|c|c|c|c|}
\hline \multicolumn{5}{|c|}{ Costo por km recorrido y por pasajero } \\
\hline $\begin{array}{c}\text { Con EE a } \\
(\mathbf{\$} / \mathbf{k W h})\end{array}$ & $\mathbf{U S D} / \mathbf{k m}$ & $\mathbf{U S D} / \mathbf{p a s}$ & $\mathbf{\$} / \mathbf{p a s}$ & Producción $\mathbf{H}_{\mathbf{2}}$ \\
\hline 233 & 1,14 & 0,41 & 773 & Descentralizada \\
\hline 69 & 0,76 & 0,27 & 510 & Centralizada \\
\hline 50 & 0,71 & 0,25 & 478 & Centralizada \\
\hline $\begin{array}{c}\text { Con GN a } \\
(\$ / \mathrm{m} 3)\end{array}$ & $\mathbf{U S D} / \mathbf{k m}$ & $\mathbf{U S D} / \mathbf{p a s}$ & $\mathbf{\$} / \mathbf{p a s}$ & Producción $\mathbf{H}_{\mathbf{2}}$ \\
\hline 642 & 0,92 & 0,33 & 619 & Descentralizada \\
\hline 450 & 0,87 & 0,31 & 585 & Descentralizada \\
\hline 255 & 0,84 & 0,30 & 569 & Centralizada \\
\hline
\end{tabular}

Tabla 8. Costo por kilómetro recorrido y por pasajero para una flota de 20 buses con celdas de combustible.

Fuente: Elaboración propia.

\section{CONCLUSIONES}

La inclusión en Colombia de una flota de transporte con celdas de combustible depende del desarrollo tecnológico logrado en otros países, del desarrollo del mercado a nivel mundial y de los precios establecidos a nivel interno para la energía eléctrica y el gas natural. Al día de hoy (junio de 2013) la tarifa promedio para un pasajero es de $\$ 1700$ para bus convencional y para el sistema de transporte público denominado metro. Los costos obtenidos en el análisis de las celdas de combustible parecen dar una factibilidad económica a la implementación de un sistema de este tipo. Los costos para la empresa de transporte cuando se produce el hidrógeno con energía eléctrica pueden variar entre \$478/pasajero cuando hay una producción centralizada de hidrógeno y \$773/pasajero cuando hay una producción descentralizada. Si el hidrogeno es producido a partir del gas natural los costos pueden variar entre $\$ 569 /$ pasajero y $\$ 619 /$ pasajero. Si se supone que el precio de los buses es de 1'500.000 USD el costo por kilómetro puede ser entre $\$ 1349 / \mathrm{km}$ y $\$ 2166 / \mathrm{km}$. El costo de la energía eléctrica y del gas natural sigue teniendo un gran impacto dentro del sistema de costos de un sistema de transporte con celdas de combustible. Esto puede hacer que la participación del costo del combustible dentro del sistema integrado pueda ir desde 31 a $57 \%$. Sí al aspecto económico se le suman los beneficios ambientales, salud, calidad de vida y de seguridad energética al hacer una diversificación de la misma; el proyecto de las celdas de combustible puede ser potenciado introduciendo políticas ambientales y económicas que estimulen su implementación.

El modelo económico desarrollado para evaluar el costo de una flota de buses, permitió realizar diferentes sensibilidades donde se pueden combinar una serie de supuestos con el valor que pueden tomar las principales variables que lo componen. Los resultados obtenidos guardan consistencia con proyectos que ya están implementados en otros países. Por ejemplo en los análisis realizados para el Valle de Aburrá donde se encontró que el proyecto para 20 buses puede variar entre $26^{\prime} 441.590$ y $42^{\prime} 784.246$ USD, guarda aceptables proporciones con el desarrollado en Brasil que tuvo un costo de 2 millones dólares por bus. El modelo puede ser aplicado para realizar no solo el análisis de los 20 buses sino que se puede aplicar para analizar cualquiera de los casos presentados en la tabla 5 .

Las diferentes fuentes consultadas evidencian que en el mundo hay un gran interés por el desarrollo de las celdas de combustible. Este interés se manifiesta en intensidad de inversiones realizadas por gobiernos, empresas y organizaciones en el desarrollo de tecnología e investigación. Las celdas de combustible presentan una atractiva alternativa que posibilita el desarrollo de sistemas más eficientes y benignos con el medio ambiente y la disminución de la dependencia de combustibles derivados del petróleo. 
El mercado de las celdas de combustible tiene un gran potencial en el sector transporte, existen bastantes proyecciones del desarrollo para este mercado. Las compañías que fabrican las celdas de combustible y vehículos que usan esta tecnología; están a la expectativa del lanzamiento comercial de sus productos pero ninguno se ha atrevido a hacerlo decididamente. Esto ocasiona que el inicio del desarrollo del mercado se prolongue ante las diferentes proyecciones que se han realizado.

Es claro que la utilización masiva de celdas de combustible requiere un proceso donde ocurran mejoras tecnológicas enmarcadas en la reducción de precios al aumentar la producción.

A la hora de evaluar un proyecto de celdas de combustible no se debe incluir solamente el costo de los automotores; se debe incorporar al estudio; los beneficios de tener por lo menos, el doble de la eficiencia de un vehículo convencional, lo que se traduce en un menor consumo de combustible para la misma distancia recorrida. Se recomienda hacer un estudio que abarque por completo la vida útil del vehículo. En este sentido se puede pensar en la ventaja de utilizar el hidrógeno como vector energético y el cual puede disminuir sus costos de producción sobre todo cuando se utilizan los excedentes de la materia prima para producirlo; tal es el caso de la producción de energía eléctrica a partir de las fuentes hídricas o las turbinas de viento. En el inicio del mercado de las celdas de combustible es indispensable la definición de políticas gubernamentales que impulsen el desarrollo de nuevos proyectos. Estas políticas se pueden manifestar en inversión directa, expedición de leyes que incentiven la implementación de tecnologías limpias y otras que regulen el uso de tecnologías que contaminan y que son menos eficientes. Los beneficios directos a obtener por impulsar el desarrollo de las celdas de combustible son: disminución de impacto ambiental, disminución de la dependencia de recursos no renovables y desarrollo económico.

En la actualidad, muchos sectores de la industria están utilizando las celdas de combustible, en el mundo el mercado de esta tecnología está en continuo crecimiento, las empresas de diferentes sectores están aumentando las inversiones para incorporarlas como apoyo a los procesos que desarrollan. Las celdas de combustible están impulsando las empresas por que les está permitiendo ahorrar dinero, tiempo, y emisiones de $\mathrm{CO}_{2}$, así como están facilitando la reactivación la industria. Se suma a esto el aumento en la fiabilidad de producción, la eficiencia y la mejorara de la imagen pública al reducir su huella de carbono en sus procesos productivos, estas compañías están ahorrando millones de dólares mientras reducen en miles de toneladas las emisiones a la atmosfera. Las celdas de combustible también están permitiendo que otras fuentes renovables sean aprovechadas con más intensidad, por ejemplo; facilitan almacenar la energía del sol y del viento. Las celdas de combustible se están masificando, incluso con el uso en el sector residencial lo que está permitiendo la obtención de economías de escala para disminuir los costos de producción de estas. Los gobiernos donde se tienen este tipo de proyectos están facilitando su desarrollo por medio de programas de financiación, regulación e incentivos [9].

En diferentes tipos de proyectos, las principales empresas productoras de autos siguen introduciendo buses y vehículos que funcionan con celdas de combustible. A su vez, en las ciudades donde se introducen estos vehículos; se instalan estaciones de suministro de hidrógeno para atender la demanda.

\section{REFERENCIAS}

[1]. Van Vliet, O., Kruithof, T., Turkenburg, W., \& Faaij, A. (2010). Techno-economic comparison of series hybrid, plugin hybrid, fuel cell and regular cars. Journal of Power Sources, 195, 6570-6585.

[2]. Kruger, P. (2006). Alternative energy resources, the quest for sutainable energy (1 ed.). USA: John Wiley \& Sons.

[3]. Giddey, S., Badwal, S., Kulkarni, A., \& Munning, C. (2012). A comprehensive review of direct carbon fuel cell technology. (Elsevier, Ed.) Progress in Energy and Combustion Science, 38, 360- 399.

[4]. Wang, Y., Chen, K. S., Mishler, J., Cho, S., \& Cordobes, X. (2011). A review of polymer electrolyte membrane fuel cells: Technology, applications, and needs on fundamental research. (Elsevier, Ed.) Applied Energy, 88, 981-1007.

[5]. DOE. (2013). 2012 Fuell Cell Technologies Market Report. Reporte, U.S. Department of Energy (DOE), Washington.

[6]. DOE. (2011). The Department of Energy Hydrogen and Fuel Cells Program Plan. An Integrated Strategic Plan for the Research, Development, and Demonstration of Hydrogen and Fuel Cell Technologies, U.S. Department of Energy, Washington. Recuperado el 14 de Mayo de 2014, de www.hydrogen.energy.gov

[7]. IEA. (2005). Prospects for hydrogen and fuel cells. (E. I. Agency, Ed.) Paris, Francia: Stedí Média.

[8]. IEA. (2001). Toward a sustainable energy future. (I. E. Agency, Ed.) Paris.

[9]. Fuelcell. (2011). State of the states: fuel cells in america. Fuelcells2000.

[10]. De la Torre, J. (4 de marzo de 2014). Instituto de cinecia y tecnología para el desarrollo. Obtenido de 
http://incytde.org/incytde/content/celdas-de-combustibleparte-3-mercados

[11]. DOE. (2013). Program Record (Offices of Vehicle Technologies \& Fuel Cell Technologies). U.S. Department of Energy.

[12]. Bravo, J. (2006). Hidrogeno y Pilas de Combustible, Estudio de Prospectiva. Madrid: Fundación OPTI, CIEMAT e INASMET-TECNALIA. http://www.opti.org.

[13]. Lucas, F. J. (2004). Propuesta de una acción en el transporte urbano de Valladolid basada en el uso de hidrógeno electrolítico obtenido mediante energía eólica. Informe.

[14]. Weaber, G. (2002). World fuel cells an industry profile with market prospects to 2010 . Fuel cell bulletin.

[15]. DOE. (2013). Program Record (Offices of Vehicle Technologies \& Fuel Cell Technologies). U.S. Department of Energy.

[16]. Bruni, G., Cordiner, S., Galeotti, M., Mulone, V., Nobile, M., \& Rocco, V. (2014). Control Strategy Influence on the Efficiency of a Hybrid Photovoltaic-Battery-Fuel Cell System Distributed Generation System for Domestic Applications. Energy Proced, 45, 014) 237.

[17]. Landirezo. (8 de julio de 2009). BRASIL: En las calles primer bus a hidrógeno de la región. Recuperado el 20 de Febrero de 2012, de http://www.landirenzo.com.br/es/?target=noticias_interno\&ci $\mathrm{d}=15$

[18]. Román, L. F. (2009). Manual básico de matemáticas finacieras. Medellín: Instituto Tenológico Metropolitáno.

[19]. M.H. Khoshgoftar Manesha, S. K. (2013). A new targeting method for estimation of cogeneration potential and total annualized cost in process industries. (Elsevier, Ed.) Chemical Engineering Research and Design (91), 1039-1049.

[20]. RITA. (2003). Research and Innovative Technology Administration. Recuperado el 19 de Abril de 2011, de http://www.bts.gov/publications/national_transportation_statis tics/2003/html/table_04_15.html.

[21]. López, G. (2009). Producción de hidrógeno por reformado de etanol sobre catalizadores Ni-SBA-15 preparados por síntesis directa. Trabajo fin de carrera.

[22]. Bockris, J. O., \& Reddy, A. K. (2003). Electroquímica moderna (Vol. 2). Barcelona, España: Reverté.S.A. 